\title{
Optimization of a warehouse layout used for storage of materials used in ship construction and repair
}

Optimización del esquema de bodegas utilizadas para el almacenamiento de materiales de construcción y reparación naval

\author{
Wilson Adarme Jaimes ${ }^{1}$ \\ María A. Otero Pineda ${ }^{2}$ \\ Tania A. Rodríguez Quiñones ${ }^{3}$ \\ Lien Tejeda López ${ }^{4}$
}

\begin{abstract}
The paper shows the evaluation of applying models to improve efficiency in management of warehouses used in shipyards, focused on pick up, packing, and shipping activities, supported among others on the proposal by Rosenblatt and Roll (1984) to optimize the layout for storage and handling of materials needed for ship construction and repair. Besides proposing the best physical layout for the storage of goods, the model seeks to minimize three types of costs: costs related to the initial investment (construction and maintenance), shortage costs, and costs associated with storage policies. The optimal design is found through analytical optimization and simulation techniques.
\end{abstract}

Key words: Warehouse, Storage, Rosenblatt and Roll model, Ships

\section{Resumen}

El articulo muestra la evaluación de la aplicación de modelos para mejorar la eficiencia en el manejo de bodegas utilizadas en astilleros, centrada en actividades derecolección, embalaje y envío, soportada entre otras en la propuesta de Rosenblatt y Roll (1984) para la optimización del diseño para el almacenamiento y manejo de los materiales necesarios para la construcción y reparación de buques. Además de proponer la mejor distribución física para el almacenamiento de las mercancías, el modelo busca minimizar tres tipos de costos: costos asociados a la inversión inicial (construcción y de mantenimiento), un costo de escasez y los costos asociados con las políticas de almacenamiento. El diseńo óptimo se desarrolla con una combinación de optimización analítica y técnicas de simulación.

Palabras claves: Bodega, Almacenamiento, Modelos de Rosenblatt y Roll, Buques

Date Received: November 22th, 2010 - Fecha de recepción: 22 de Noviembre de 2010

Date Accepted: February 4th, 2011 - Fecha de aceptación: 4 de Febrero de 2011

\footnotetext{
${ }^{1}$ Universidad Nacional de Colombia Sede Medellín, Facultad de Minas. Medellín, Colombia. e-mail: wadarmej@unal.edu.co

${ }^{2}$ Universidad Nacional de Colombia Sede Bogotá, Facultad de Ingeniería. Bogotá, Colombia. e-mail: maoterop@unal.edu.co

${ }^{3}$ Universidad Nacional de Colombia Sede Bogotá, Facultad de Ingeniería. Bogotá, Colombia. e-mail: trodriguezq@unal.edu.co

${ }^{4}$ Escuela Naval Almirante Padilla. Cartagena, Colombia. e-mail: ltejeda@cotecmar.com
} 


\section{Introduction}

The analysis of warehouses refers to the location of the various departments (reception, selection, storage, sorting, and shipping), as well as to their distributions. The common goal is to minimize handling costs, which in many cases are represented by a linear function of the distances covered and that in terms of logistics costs can represent up to $20 \%$. Tompkins et al., (2003) state that the purpose of the layout is to minimize handling costs, generally represented by a linear function of the distance traveled.

In the design of a warehouse/storage building should consider the overall structure, size and dimension, features of departments, selection of its strategic operation, and equipment to be used in the storage process. During the overall design, material flow patterns, functions of each department (reception, selection, storage, sorting, and shipping), and the relationships flow that should exist among its sections is determined. Activities of receiving and pick up, (Pick up/Packing) are considered relevant given the cost implications involved and these are influenced and affected by the type of warehouse design considered.

$\mathrm{Gu}$ and Goetschalckx (2010) discussed the design of the storage department and typify the main problems to be solved, classifying them thus: identify storage stacking platform, depth of storage lanes, and existing number of lanes. Other issues to be solved are location of the main entrance door, orientation of lanes, and number of lanes that must exist throughout the warehouse. Finally, the number of cranes and the dimensions of storage racks mmust be addressed.

The design of the storage department exposed by $\mathrm{Gu}$ and Goetschalckx (2010) affects the performance of the warehouse with respect to construction costs, holding costs, labor costs, storage capacity, use of space, and use of equipment.

The Rosenblatt and Roll (1984) model seeks an optimal solution to the physical layout and design of a storage building, considering the amount of entry and exit ways, the location of these doors, the number of aisles and their orientation and dimensions. It also takes into account the warehouse capacity and storage policies, as decision variables to apply optimization techniques that are characteristic of the model. The Rosenblatt and Roll (1984) model proposes optimization of three types of costs: Costs associated with the initial investment (construction and maintenance), shortage costs, and costs associated with storage policies. The subsequent investigation to find the optimum design of storage is developed by comparing analytical optimization and simulation techniques.

The type of storage building that Rosenblatt and Roll (1984) have proposed in their model is a warehouse with only one physical plant, where products can be arranged on shelves with a calculated amount of levels, on pallets or stacked. Besides, it must be taken into account that this model considers the random storage policy where, in areas dividing the warehouse, goods can be randomly arranged; no considerations are made about the composition of products or how they should be accommodated. In this model, equipment for handling and internal transport of goods should be available, especially when considering high shelves to store products, to take advantage of all the warehouse space and decrease the number of shipments rejected because of lack of space. This equipment permits access to products in high places, leading to good inventory turnover.

The model is a good study reference because, in addition to proposing different types of layouts and providing the best physical space for storage of goods, it intends to minimize three major costs in terms of design, material handling, and storage; therefore, it is considered a prototype model that combines important aspects of interest to current companies that seek storage solutions while minimizing operating costs.

\section{Literature review}

According the Layout topic, relevant studies in this field are described; the Rosenblatt and Roll (1984) model simultaneously addresses three objectives: warehouse size, internal distribution, and storage 
policies. The literature dealing with layout problems is combined with traditional storage processes (pick up, packing, shipping), describing the complexities of these activities and the need to address these issues jointly.

Berry (1968) found that warehouse distribution could minimize maintenance costs of materials. Francis (1967), Francis and White (1974), Roberts and Reed (1972), and Bassan, Roll and Rosenblatt (1980) found the design of the internal layout of a warehouse to minimize its construction costs and handling costs for materials. Several designs of the internal layout of a storage building have been compared (Bassan, Roll and Rosenblatt; 1980), where the effects of the costs where associated to the perimeter of the storage and the materials handling but are not associated to the cost of the warehouse area. This is consistent with Francis (1967), who assumed that the storage area is predetermined and considered only the costs of materials handling and costs of the perimeter. The problem of warehouse size was considered by White and Francis (1971). The costs considered on their study were, construction costs, assuming they are proportional to store size, storage costs, and evaluation costs - when there is a shortage of available space for storage. A Roll and Rosenblatt (1983) document compares a series of storage policies and their effects in the capacity of a warehouse. Hausman, Shwarz, and Graves in two of their papers $(1977,1976)$ developed rules for optimal allocation of storage and the sequence of storage in a warehouse of auto design(WHAT DO YOU MEAN BY THIS?). To assume feedback knowledge for various products (or product groups), they developed storage allocation and intercalated policies that achieve significant reduction in travel time of a crane.

Tompkins et al., (2003) described different effective procedures for layout design; Heragu et al., (2005) provided a model and a heuristic for the dimensioning of areas and the allocation of products to the areas. In general, the design of internal arrangement, or aisle configuration problem, which includes determining the number of blocks, number, length and width of aisles in each block is depicted in Fig. 1.

Roodbergen (2001) proposed a nonlinear objective function (the average travel time in terms of the number of collections (pickups) by trade and

Fig 1. Location Decisions

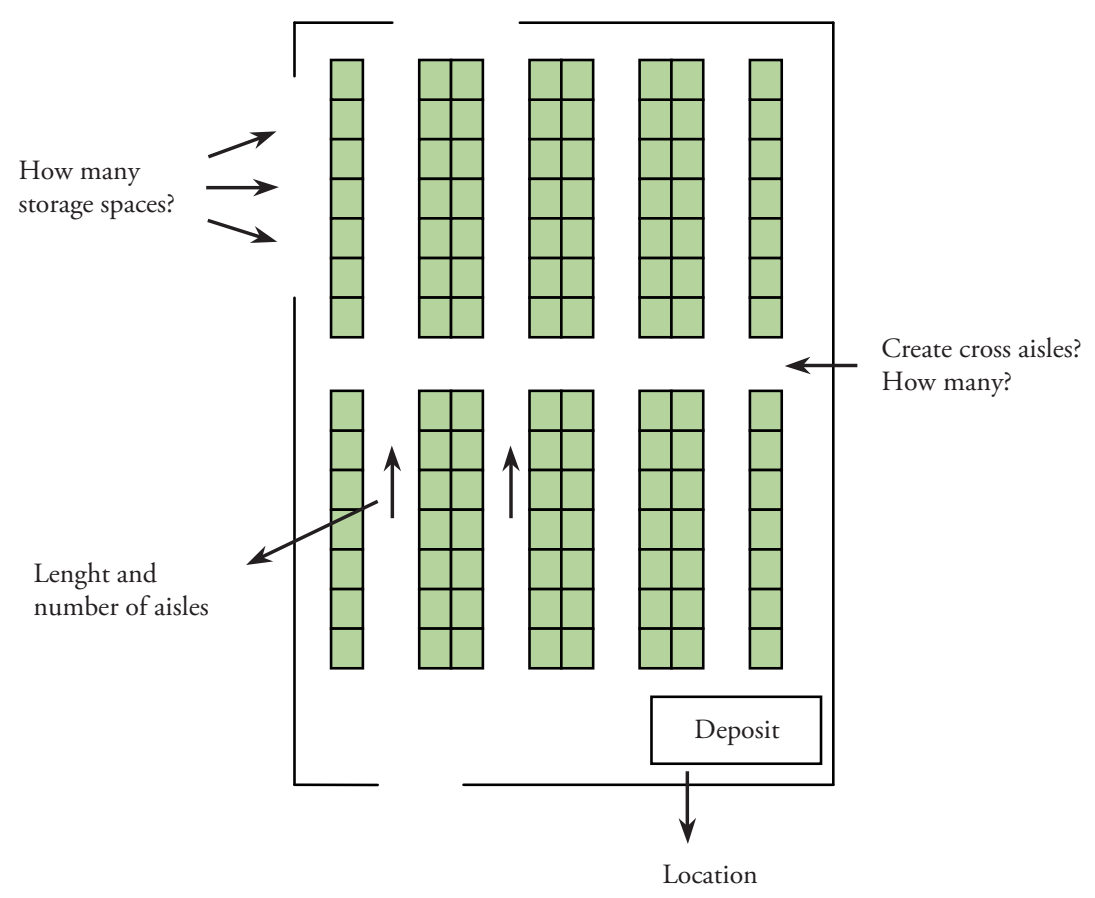

Source: Authors 
islands) to determine aisle configuration for storage deposits by using non-dedicated systems, i.e., random (including single and multiple blocks) that seek to minimize the duration of the tour.

Compared to manual pick up systems and order preparation, the layout design problem taking the load unit (Mainly Automated Storage/Retrieval Storage (AS/RS) systems) has received much attention. This case concerns investigations by Sarker and Babu (1995), Johnson and Brandeau (1996), and Van den Berg (1999).

For random storage assignment, Bozer and White (1984) show relevant studies in this regard. Larson et al., (1997) use a heuristic approach to the design of the load unit in a warehouse and to assign types of goods to locations, in order to increase space utilization and reduce travel distance.

Eldemir etal., (2004) give estimates of storage needs. Park and Webster (1989) address the problem of finding locations for types of products to minimize travel time. De Koster and Le-Duc (2005) extend Bozer and White (1984) to determine the optimal size of a rack of three dimensions of capacity and to minimize recovery time of the load unit.

Reiterating on the Rosenblatt and Roll (1984) model, two data sets are assumed to be known for the procedure. The first data set consists of the distributions that govern the arrival and the composition of products to be stored. The second is the set of approximate cost models, combining the cost components to the configuration of the distribution, storage policies, and shortage in storage capacity. An approximate combination of optimization techniques is applied to determine the total cost as a function of two decision variables: capacity of warehouse and storage policies. Then, by comparing the costs of possible combinations of these variables, we obtain a global optimum storage size, configuration, and storage policies.

Literature on these issues is abundant; however, it is found that the level of application in different industries and particularly in Colombian Shipyards is very low. Publications like those by Bassan et al., (1980) and Rosenblatt and Roll (1984) use analysis and simulation methods to study the effects of the storage policy (i.e., how to assign products to storage locations) in relationship to the internal storage design. Also, Rosenblatt and Roll (1988) examined the effect of stochastic demands and different levels of service in the warehouse layout and storage capacity.

This literature review on layout investigations shows the relevant studies by Bassan, Rosenblatt and Roll that serve as pivot for the analysis involved in the characterization and improvement proposal for COTECMAR, adjusted to the conditions of existing resources and the size of the configuration presented by the central warehouse of the Corporation.

\section{Nomenclature and basic models}

Based on the figure below, for a rectangular warehouse with a W width and an L length, with floor area of $S$, the following relationships were found:

Fig 2. Size of a rectangular warehouse

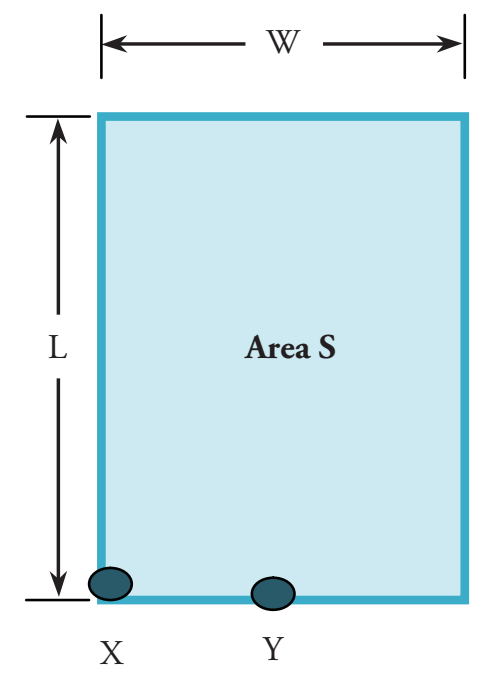

Source: Authors

$\mathrm{C}=$ Sum of total cost per unit of length to move an item multiplied by the expected number of items per year $(\$ / \mathrm{ft})$

$\mathrm{K}=$ annual cost of perimeter $(\$ / \mathrm{ft})$

$\mathrm{S}=$ Area of the warehouse $\left(\mathrm{ft}^{2}\right)$ 
$\mathrm{CT}_{\mathrm{X}}, \mathrm{CT}_{\mathrm{Y}}=$ total relevant cost for setting $\mathrm{X}, \mathrm{Y}[\$ /$ year]

Exit/Entry Door located in X:

$$
\begin{aligned}
& W^{*}=\sqrt{\frac{C+8 k}{2 c+8 k}} \sqrt{S} \\
& L^{*}=\frac{L}{W^{*}} \\
& C T_{x}=2 \sqrt{\left[\frac{C}{2}+2 K\right]\left[\frac{C}{4}+2 K\right]} \sqrt{S}
\end{aligned}
$$

Exit/Entry Door located in Y:

$$
\begin{aligned}
& W^{*}=L^{*}=\sqrt{S} \\
& C T_{y}=\left[\frac{C}{2}+4 K\right] \sqrt{S}
\end{aligned}
$$

\section{Shelf and aisle configuration - Notation}

$\mathrm{W}=$ width of a double-sided shelf [ft]

$\mathrm{L}=$ length of each storage space (for example, the width of a pallet $[\mathrm{ft}]$ )

$\mathrm{m}=$ Number of storage spaces along a shelf

$\mathrm{h}=$ Number of storage levels in the vertical direction

$\mathrm{n}=$ number of double-sided shelves, two simple shelves are considered equal to a double shelf

$\mathrm{K}=$ total capacity of storage space in the warehouse $\mathrm{a}=$ width of an aisle [feet], assuming that all have the same width

$\mathrm{u}=$ length of the warehouse $[\mathrm{ft}]$

$\mathrm{v}=$ width of the warehouse $[\mathrm{ft}]$

$\mathrm{d}=$ annual demand of the warehouse in storage units (e.g., pallets). It is assumed that a storage item uses a storage unit [items/year]

$\mathrm{Ch}=$ cost of material handling, of moving an item a unit of length $[/ \mathrm{ft}]$

$\mathrm{Cs}=$ annual cost per unit area of the warehouse, for example: air conditioning, electricity, maintenance $\left[\$ / \mathrm{ft}^{2}\right]$

$\mathrm{Cp}=$ annual cost per unit of length of external walls $[\$ / \mathrm{ft}]$

The optimal number of storage spaces depends on the distribution figure adopted; a typical example for a situation with aisles in front of the door:

$$
m_{1}^{*}=\frac{1}{L} \sqrt{\left[\frac{d C_{b}+2 a C_{s}+2 C_{p}}{2\left(d C_{h}+C_{p}\right)}\right]\left[\frac{K(w+a) L}{2 h}\right]}
$$

And the optimal number of double-sided shelves is:

$$
n_{1}^{*}=\frac{1}{w+a} \sqrt{\left[\frac{2\left(d C_{b}+2 C_{p}\right)}{d C_{b}+2 a C_{s}+2 C_{p}}\right]\left[\frac{K(w+a) L}{2 h}\right]}
$$

Thus, the best configuration of the warehouse would have an optimum length of:

$$
u_{1}^{*}=n_{1}^{*}(w+a)
$$

And an optimum width of:

$$
v=2 a+m_{1}^{*} L
$$

For cross-aisle layout, the optimal results are:

$$
\begin{aligned}
& m_{2}^{*}=\frac{1}{L} \sqrt{\left[\frac{2 d C_{b}+3 a C_{s}+2 C_{p}}{d C_{b}+2 C_{p}}\right]\left[\frac{K(w+a) L}{2 b}\right]} \\
& n_{2}^{*}= \frac{1}{w+a} \sqrt{\left[\frac{d C_{b}+2 C_{p}}{2 d C_{b}+3 a C_{s}+2 C_{p}}\right]\left[\frac{K(w+a) L}{2 h}\right]} \\
& u_{2}^{*}=3 a+m_{2}^{*} L \\
& v_{2}^{*}=n_{2}^{*}(w+a)
\end{aligned}
$$

To minimize costs between these two alternative designs, the following decision rule can be applied:

- If $\mathrm{d}<\mathrm{Cp} / \mathrm{Ch}$, select configuration 1

- If $\mathrm{d}>2 \mathrm{Cp} / \mathrm{Ch}$, select configuration 2

- If $\mathrm{Cp} / \mathrm{Ch}<\mathrm{d}<2 \mathrm{Cp} / \mathrm{Ch}$, cannot conclude

\section{Metodology}

To propose improving the layout of the central storage warehouse oat COTECMAR, we performed in situ characterization of the infrastructure, processes, and activities associated with storage through observing them and with surveys and interviews of the staff responsible of this process within the Corporation. Fieldwork was conducted by using tools for collecting, tabulating, and analyzing data to obtain and collect information associated with the flow of materials within the warehouse, as well as in and out of it. 
Additionally, information was obtained on the logistics infrastructure of the Corporation, which included making drawings of the different storage spaces in dimensions and storage equipment to obtain the storage capacity at COTECMAR in square and cubic meters.

\section{COTECMAR's logistics infraestructure}

COTECMAR has two main headquarters located in the ports of Mamonal (Industrial Sector) and Bocagrande (Tourism Sector) in the city of Cartagena de Indias, Colombia. The company has warehouses for the storage of materials and supplies needed for operations at both sites.

At the Mamonal headquarters, there is a central storage building, a warehouse to store materials for the Offshore Patrol Vessel (OPV) construction project and areas for storage of specific materials. The central warehouse at Mamonal, the objective of this study, stores materials necessary for construction and repair projects and for the operation at the COTECMAR facilities. This warehouse has spaces for materials requiring special storage conditions.

The warehouse has a welding room equipped with temperature-control equipment to maintain the solder under controlled conditions in accordance with the specifications for these materials. Similarly, the warehouse has two rooms with air conditioning to store materials and equipment that cannot be kept at room temperature, like resins, oils, adhesives, and special material for the OPV project. These rooms also store the warehouse's physical files.

COTECMAR'S central warehouse has $1169 \mathrm{~m}^{2}$ in areas of material receipt, storage, pick up and shipping. The aggregate capacity of the central warehouse is $5369 \mathrm{~m}^{3}$.

In 2009, COTECMAR started a project of Adaptation and Modernization of the storage buildings and other storage areas. The project was designed to optimize the storage of materials
Fig 3. Central Warehouse at the Mamonal plant

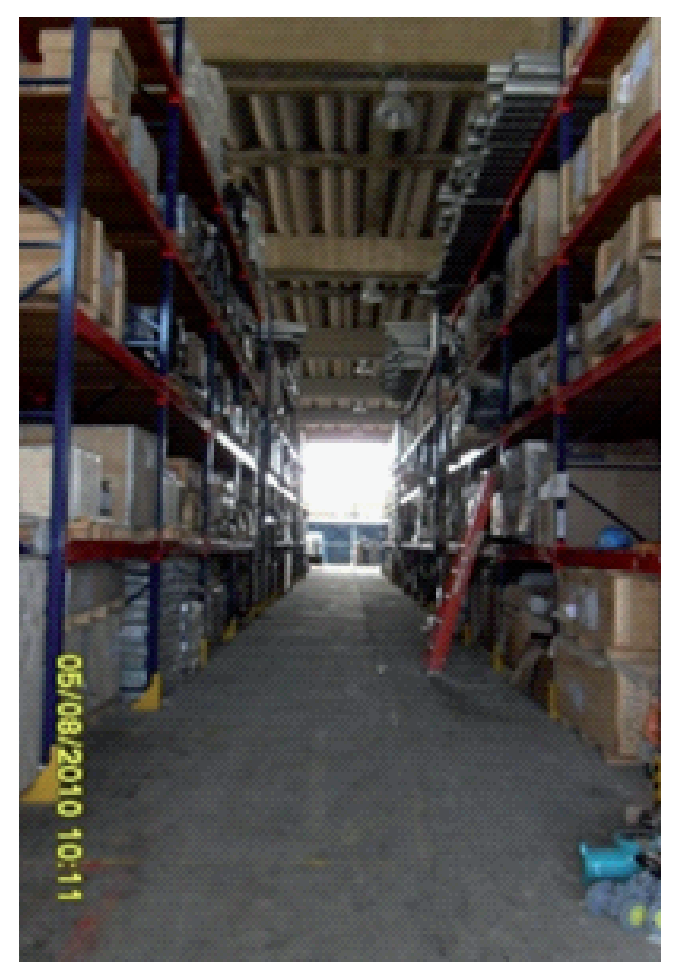

through the adaptation and modernization of the existing system to meet present and future corporate challenges. The central warehouse at the Mamonal plant has an area of $1170 \mathrm{~m}^{2}$, after the expansion and investments that included demolishing the former composites workshop and expanding the warehouse. In 2009, the area of this central warehouse was of $723 \mathrm{~m}^{2}$.

Furthermore, the way the shelves were located did not permit full maneuverability of loading equipment in the warehouse. As illustrated in Fig. 4, a whole aisle of shelves was inaccessible by the forklift because of the height conditions of the warehouse in the lateral zones. In this zone, the merchandise must be located manually by the operators, placing them at risk and rendering as inefficient the operations of material location and pick up.

Despite investments in the warehouse to be consistent with the needs of new construction projects, acquisition of handling equipment and shelving and preparation of areas for the conservation and storage of special materials 
(solder, electronic elements), the physical layout of the central warehouse at Mamonal does not follow any criteria, except for the storage of certain materials under special temperature conditions.

Fig 4. Forklift maneuverability

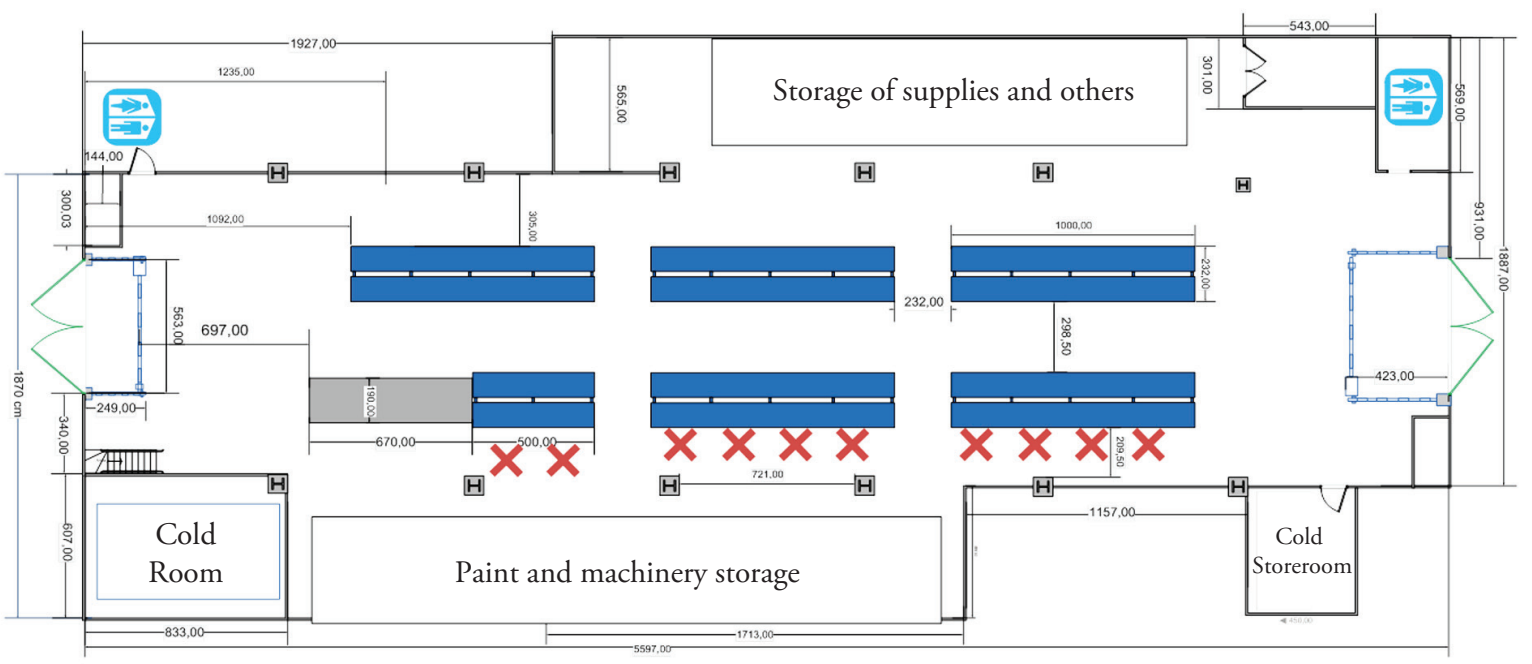

Source: SEPRO and GICO Research Group

\section{Reestructuring the layout of the central warehouse at the Mamonal plant}

The distribution of the central warehouse at the Mamonal plant is shown in Fig. 5. This arrangement has several drawbacks from the logistics point of view, which will be discussed and solved in the restructuring proposal.

The warehouse has a linear distribution, as shown in Fig. 6.

Fig 5. Current arrangement of the Cotecmar central warehouse

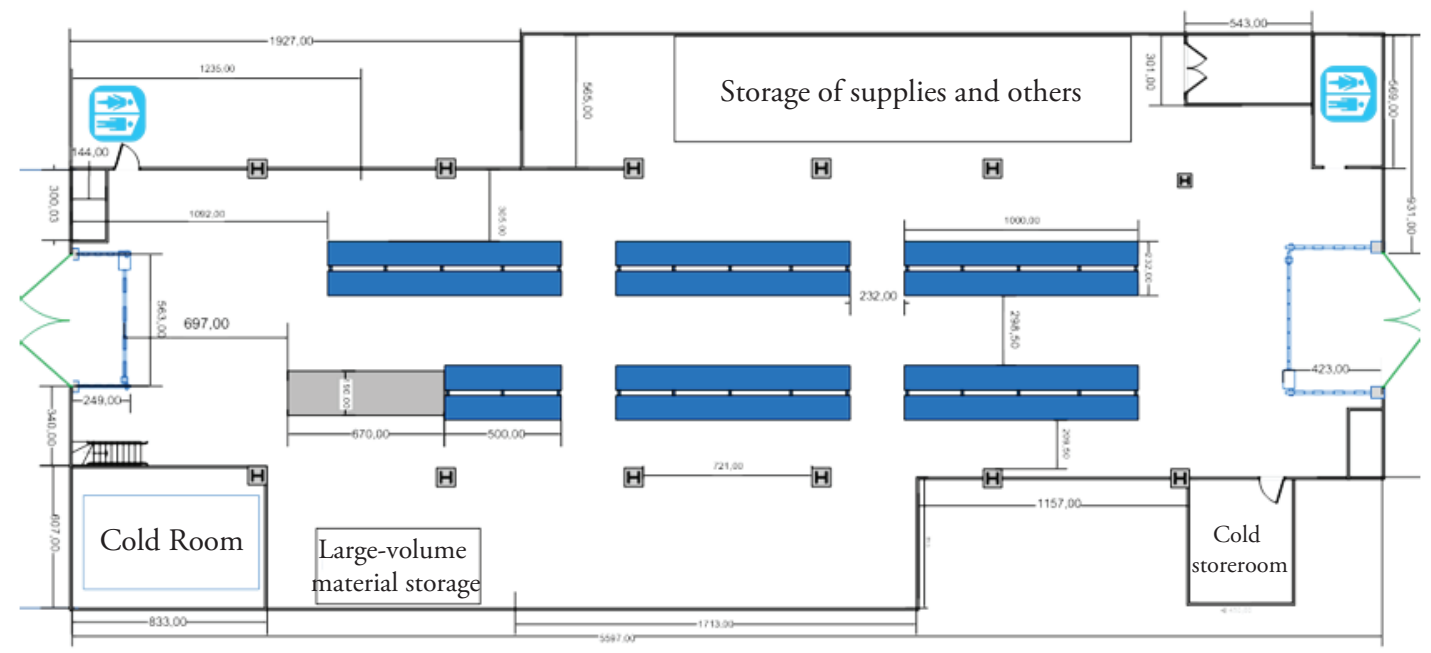

Source: GICO-SEPRO Research Group 
Fig 6. Warehouse distribution

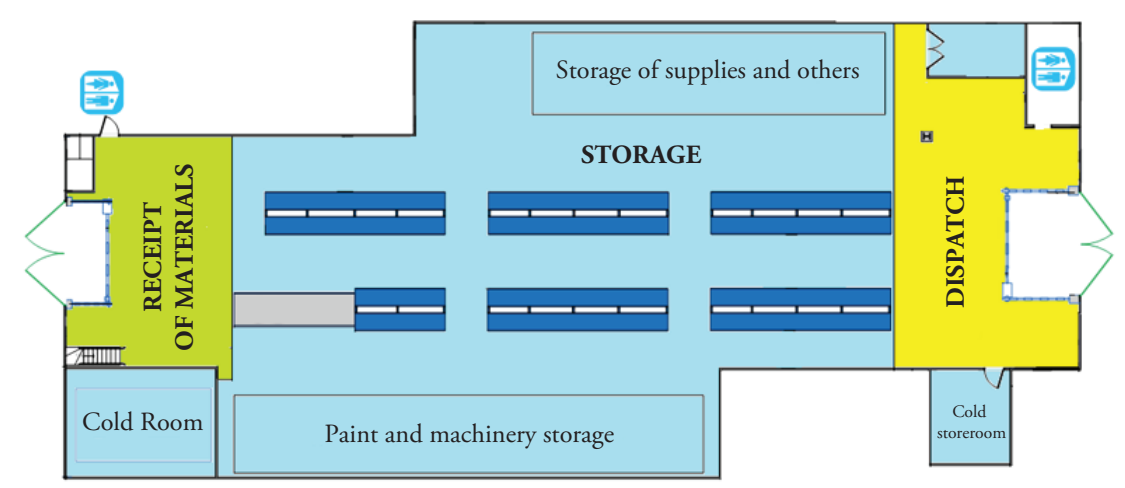

Source: GICO-SEPRO Research Group

Fig. 6 clearly identifies reception and storage of material areas, but also notable is the absence of an area to prepare orders. This can be attributed to the following problems encountered in the warehouse:

- Delays in the process of order compliance

- Aisles obstructed

- Delays in activities of storage and pick up of materials from shelves due to obstructed aisles

- An obstructed aisle means three things for the warehouse: 1 . Higher costs of internal transportation of materials; 2. Decrease in the amount of usable space in the warehouse; 3. Expenditure on(NOT CLEAR) staff resource, which can be used in other functions such as cleaning or performance improvement activities in the warehouse.

To tackle these problems, we recommend clearly establishing the order preparation area. The size of the pickup area should be as shown in Fig. 7.

Fig 7. Redistribution of warehouse zones

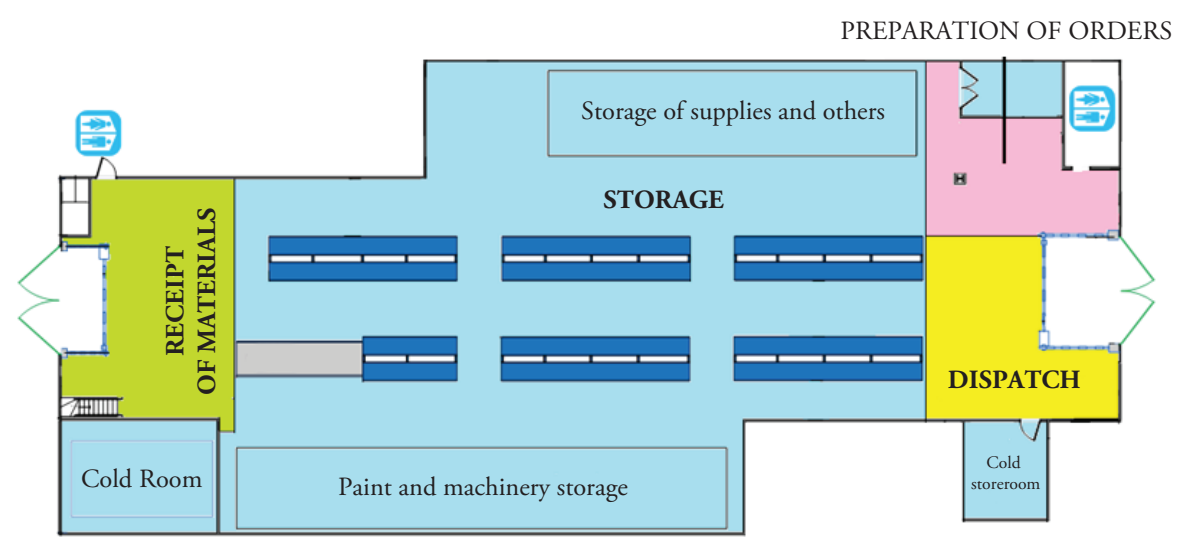

Source: GICO-SEPRO Research Group

According to this figure, we can determine that:

- For the operating conditions of the warehouse, the area designated for the reception is properly sized.

- The area dedicated solely to delivery, under the present conditions, must be shared with the area allocated for pickups or order preparation. Thus, before shipping an order, it should be organized and processed in this new area. 
With the setting recommended, mainly referring to Rosenblatt and Roll, the order preparation area allows accommodating up to 10 pallets of temporary storage, permitting normal operation with the forklift for seven of them, as shown in
Fig. 8. These 10 pallets provide sufficient space to ensure that any order can be prepared in that area, preventing obstruction of the aisles during the process of collecting materials in the warehouse.

Fig 8. Structuring the pickup area

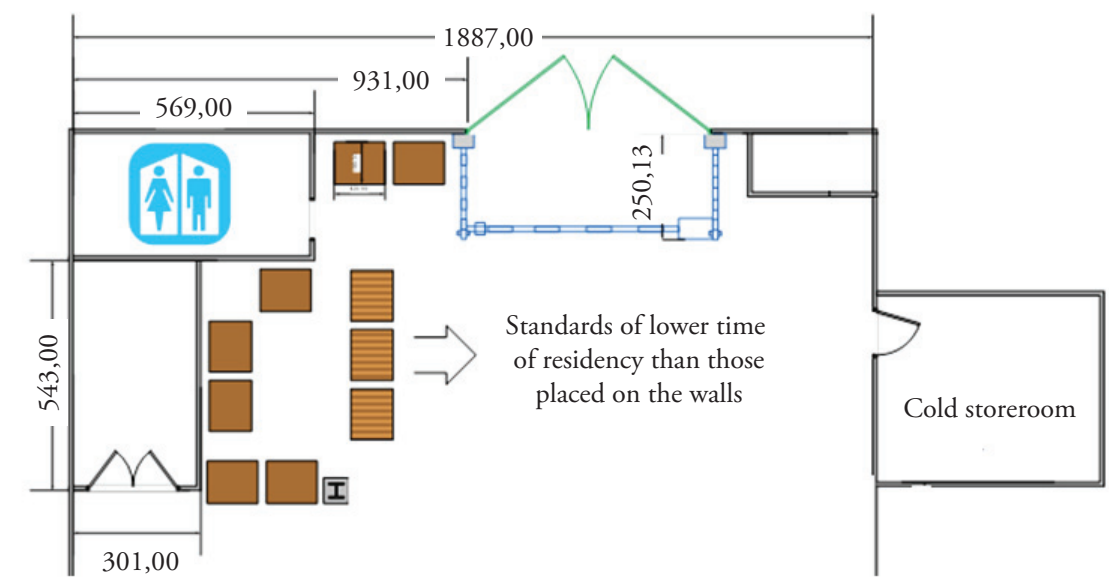

Source: GICO-SEPRO Research Group

In order to increase storage capacity and mobility restructuring the layout is proposed, as shown in of the central warehouse at the Mamonal plant, Fig.9.

Fig 9. Restructuring the central warehouse at the Mamonal plant

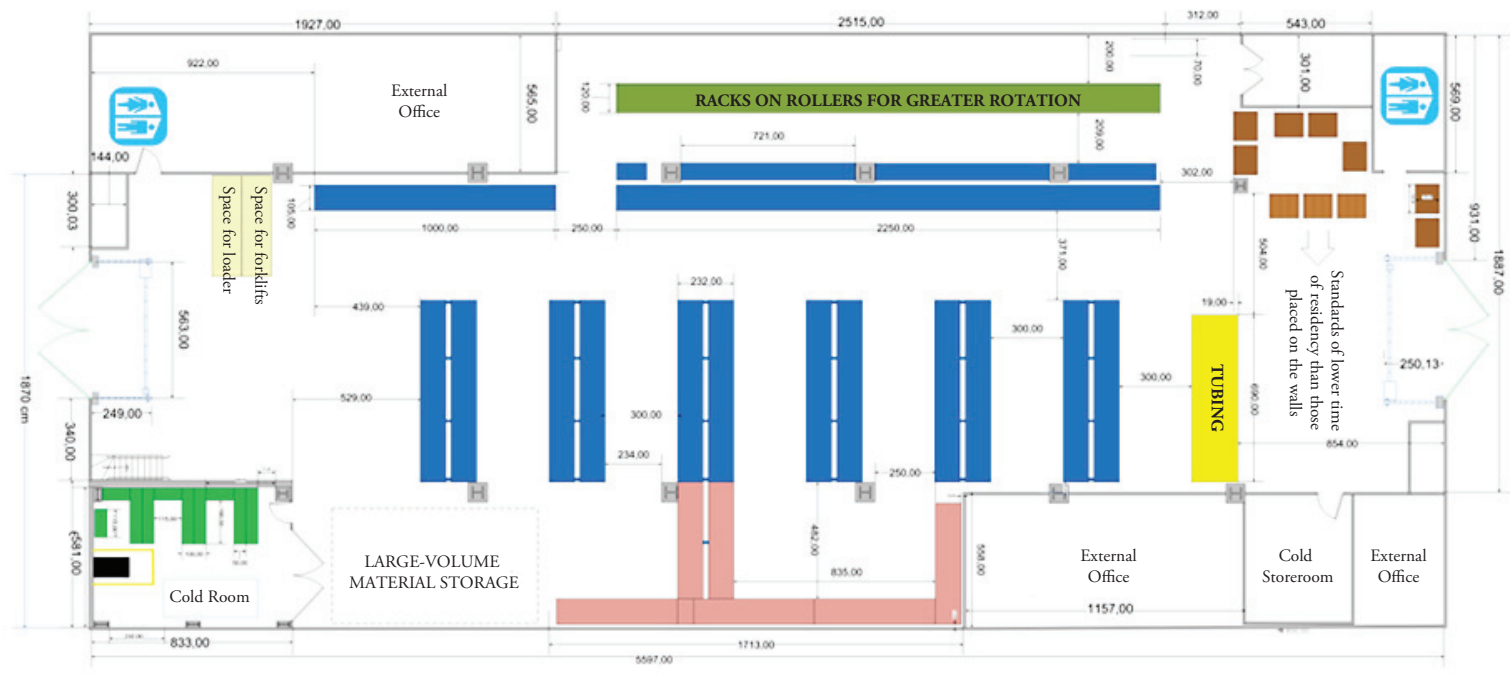

Source: GICO-SEPRO Research Group

This restructuring comprises several changes, f) Maximum use of the volume of the warehouse. which allow achieving the following objectives:

g) Use of all storage shelves. 
h) Improve mobility in the warehouse.

i) Improve reception, dispatch, and order pick up areas.

j) Adjust and improve the storage areas of paints and screws.
The central rack, in blue in Fig. 9, is responsible for storing the materials that can be stored on pallets and that have regular dimensions. Table 1 furnishes a summary of current variables and those provided by the new distribution.

Table 1. Comparison of current storage model and the one proposed

\begin{tabular}{|c|c|c|}
\hline Description & Current & Proposed \\
\hline Possible storage positions & 208 & 245 \\
\hline Obstructed positions & 48 & 0 \\
\hline$\%$ Obstructed positions & $23 \%$ & $0 \%$ \\
\hline Positions actually used & 160 & 245 \\
\hline Increase in the number of positions & \multicolumn{2}{|c|}{$18 \%$} \\
\hline REAL INCREASE (Real storage positions) & \multicolumn{2}{|c|}{$53 \%$} \\
\hline
\end{tabular}

Source: GICO-SEPRO Research Group

The area of material on consignment is configured as shown in pink in Fig. 9. This design corresponds to a better use of space, allowing the entry of the forklift because most of the materials coming into this area are paints, which very often enter the warehouse organized in pallets. Furthermore, this structure is according to the organization of the central shelf, allowing greater mobility and flexibility for daily operating activities in the warehouse. The shelf corresponding to this area is the same as that established for the central storage area, allowing the possibility of storage during a peak period, so palletized materials can be stored in this area due to the possibility of forklift maneuverability, which provides flexibility to the warehouse.

The physical file storage area must be transferred to the cold room in the first floor of the offices according to warehouse management requirements. This requires designing the shelving necessary for the material, taking into account only the use of half the available space in the room, where there is a rack system rack - which is not removable, and the rest of the room should be used to store containers on the floor with materials that require temperature-controlled conditions. The storage volume required for the file zone is of 20.08 cubic meters. Fig. 10 shows the distribution of the shelf designed for file storage and stationery. This shelf has 5 levels, reaching a height of $2.72 \mathrm{~m}$, the shelf width is $50 \mathrm{~cm}$ and the standard length is $1.15 \mathrm{~m}$. The storage volume obtained with the proposed distribution in Fig. 10 is 21.62 cubic meters, which is completely satisfactory for the proposed storage.

Fig 10. Design of the file storage area

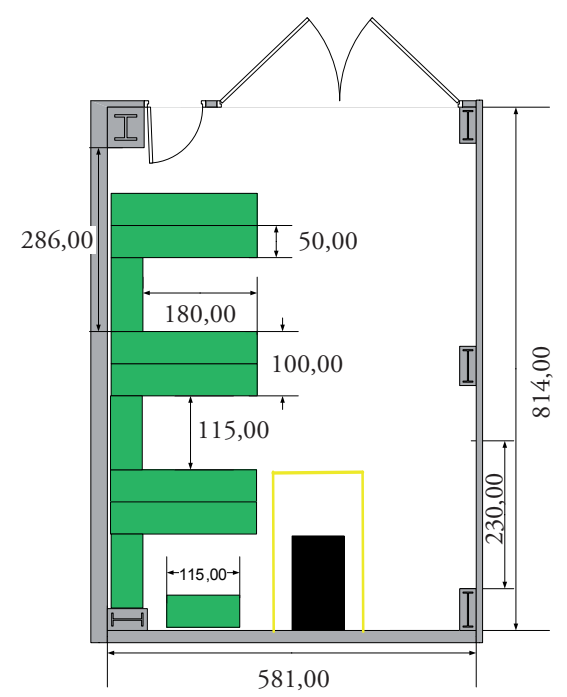

Source: GICO-SEPRO Research Group 
Fig. 11 shows the design of the storage area for screws, valves, and other materials. This design is based on using a sloping shelf (green shelf) in which the material is loaded by the side of the wall, and due to this tilt the materials will move automatically to the other side by which these elements will be removed. This will ensure that older materials are those that are taken out first, following the First In First Out (FIFO) sequence.
It is recommended that this shelf holds rollers, which facilitate moving items stored.

On the same side where the elements are removed is a conventional shelf 70 inches deep and 4 heights. This rack can store material with low turnover, while increasing storage capacity in this area of the warehouse.

Fig 11. Comparison of current storage model and the one proposed

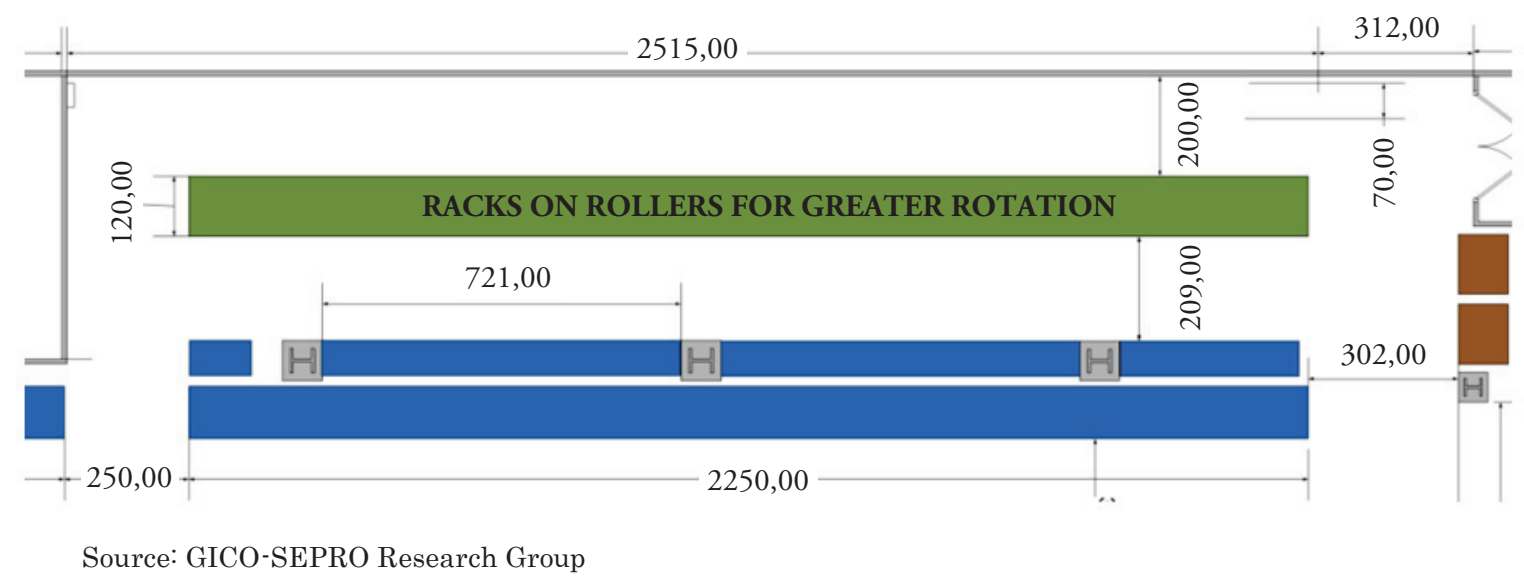

\section{Conclusions}

The restructuring of the proposed layout for the central warehouse at the Mamonal COTECMAR headquarters clearly establishes the areas in which the warehouse should be divided so that there should be an area different from order preparation to solve the problems of obstructed aisles and delays in order fulfillment and storage and collection of materials. By allocating an area for this purpose, the costs of transport of goods in the warehouse are reduced and the usable storage space is increased.

The proposed restructuring of the shelves in the area of the warehouse for the storage will also achieve a maximum use of the warehouse, ensuring accessibility of the forklift to the entire shelf and improving the provision of specific storage areas such as consignment of paints, coolers, and ironmonger area. The proposed layout design for the warehouse ensures better use of space and access to all storage areas, allowing greater mobility and flexibility for daily operating activities of the warehouse.

\section{References}

BASSAN, Y., ROLL, Y., ROSENBLATT, M.J., 1980. Internal layout design of a warehouse. AIIE Transactions 12 (4), 317-322.

BERRY, J.R., 1968. Elements of warehouse layout. International Journal of Production Research 7 (2), 105-121.

BOZER, Y.A., WHITE, J.A., 1984. Travel-time models for automated storage/retrieval systems. IIE Transactions 16, 329-338.

ELDEMIR, F., GRAVES, R.J., MALMBORG, C.J., 2004. New cycle time and space estimation models for automated storage and retrieval system conceptualization. 
International Journal of Production Research 42 (22), 4767-4783.

FRANCIS, R.L., "On some problems of rectangular warehouse design and layout," Jou. Of Ind. Eng., Vol. 18 (1967), 595 -604.

FRANCIS, R.L., 1967. On some problems of rectangular warehouse design and layout. The Journal of Industrial Engineering 18, 595604.

GU, GOETSCHALCKX AND MCGINNIS (2010) Research on warehouse design and performance evaluation: A comprehensive review European Journal of Operational Research 203 (2010) 539-549.

HERAGU, S.S., DU, L., MANTEL, R.J., SCHUUR, P.C., 2005. Mathematical model for warehouse design and product allocation. International Journal of Production Research 43 (2), 327-338.

HAUSMAN, W.H., SCHWARZ, L.B., GRAVES, S.C., 1976. Optimal storage assignment in automatic warehousing systems. Management Science 22 (6), 629-638.

JOHNSON, M.E., BRANDEAU, M.L., 1996. Stochastic modeling for automated material handling system design and control. Transportation Science 30 (4), 330-350.

LARSON, T.N., MARCH, H., KUSIAK, A., 1997. A heuristic approach to warehouse layout with class based storage. IIE Transactions 29, 337-348.
PARK, Y.H., WEBSTER, D.B., 1989. Design of class-based storage racks for minimizing travel time in a three dimensional storage system. International Journal of Production Research 27 (9), 1589-1601.

ROBERTS, S.D., REED, R., 1972. Optimal warehouse bay configurations. AIIETransactions 4 (3), 178-185.

ROODBERGEN, K.J., 2001. Layout and routing methods for warehouses. Ph.D. thesis, RSM Erasmus University, the Netherlands.

ROSENBLATT, M.J., ROLL, Y., 1984. Warehouse design with storage policy considerations. International Journal of Production.

SARKER, B.R., BABU, P.S., 1995. Travel time models in automated storage/retrieval systems: A critical review. International Journal of Production Economics 40, 173-184.

TOMPKINS, J.A., WHITE, J.A., BOZER, Y.A., FRAZELLE, E.H., TANCHOCO, J.M.A., 2003. Facilities Planning. John Wiley \& Sons, NJ.

VAN den BERG, J.P., 1999. A literature survey on planning and control of warehousing systems. IIE Transactions 31, 751-762.

WHITE, J.A., FRANCIS, R.L., 1971. Normative models for some warehouse sizing problems. AIIE Transactions 9 (3), 185-190. 